\title{
Matemática de Singapura: gamificações para o ensino fundamental
}

\author{
Germano Bruno Afonso* \\ Melissa Samantha Holetz ${ }^{* *}$
}

\section{Resumo}

O objetivo desse projeto é desenvolver um jogo para trabalhar operações matemáticas básicas e frações no Ensino Fundamental que possa ser aplicado nas escolas brasileiras usando o que foi estudado sobre a Metodologia de resolução de problemas e as ferramentas didáticas utilizadas no ensino da Matemática de Singapura. Para o desenvolvimento desse trabalho foram realizadas as seguintes atividades: levantamento de material bibliográfico baseado na análise de uma sequência de atividades selecionadas de uma coleção de livros didáticos de Singapura; investigação de uma gamificação dessa metodologia através da resolução de problemas; experimentação dessa estratégia; observação e aplicação de questionários e análise dos mesmos. Após criação e aplicação do jogo, observou-se que essa metodologia facilita o entendimento dos problemas pelos alunos, por meio do uso contínuo de desenhos, esquemas e ferramentas.

Palavras-chave: Ensino de Matemática no Ensino Fundamental. Metodologia do Ensino de Matemática de Singapura. Ensino de Matemática e Gamificação. Ensino de Matemática e Jogo.

* Pós-Doutorado em Astronomia pelo Observatoire de la Cote dAzur, França. Doutor em Astronomia de Posição e Mecânica Celeste pela Université Pierre et Marie Curie (Paris VI). Mestre em Ciências Geodésicas e Graduado em Física pela Universidade Federal do Paraná. Foi Professor Titular de Física de Universidade Federal do Paraná. Atualmente é professor/pesquisador do Programa de Pós-Graduação Stricto-Sensu: Mestrado Profissional em Educação e Novas Tecnologias - PPGENT, do Centro Universitário Internacional UNINTER, Curitiba, PR. germano.a@uninter.com

** Possui Mestrado em Educação e Novas Tecnologias, pela UNINTER, graduação em Matemática pela Universidade Federal de Santa Catarina (2000), em Pedagogia pela UNINTER (2018) e Especialização em Psicopedagogia pela Famath/RJ (2002), além de coordenação pedagógica 


\section{Singapore Mathematics: gamifying of in elementary school}

\section{Abstract}

The main objective of this project is to develop a game to work basic mathematical operations and fractions in elementary school that can be applied in Brazilian schools using what has been studied about problem solving methodology and the didactic tools used in teaching mathematics in Singapore. The following activities were carried out to develop this work: survey of bibliographic material based initially on the analysis of a sequence of activities selected from a collection of textbooks from Singapore; investigation of a possible gamification of this methodology through problem solving; experimentation with this strategy; observation and application of questionnaires and their analysis. After creating and applying the game, it was observed that this methodology facilitates students' understanding of problems through the continuous use of drawings, schemes and tools.

Keywords: Mathematics Teaching in Elementary School. Singapore Mathematics Teaching Methodology. Mathematics and Gamification Teaching. Math and Game Teaching.

\section{Matemáticas de Singapura: gamificaciones para la educación fundamental}

\section{Resumen}

El objetivo de este proyecto es desarrollar un juego para trabajar operaciones matemáticas básicas y fracciones en la escuela primaria que se pueda aplicar en las escuelas brasileñas utilizando lo estudiado sobre la Metodología para la resolución de problemas y las herramientas didácticas utilizadas en la enseñanza de las Matemáticas en Singapur. . Para el desarrollo de este trabajo se llevaron a cabo las siguientes actividades: relevamiento de material bibliográfico basado en el análisis de una secuencia de actividades seleccionadas de una colección de libros de texto de Singapur; investigación de una gamificación de esta metodología a través de la resolución de problemas; experimentación con esta estrategia; observación y aplicación de cuestionarios y análisis de los mismos. Luego de crear y aplicar el juego, se observó que esta metodología facilita la comprensión de los problemas por parte de los estudiantes, mediante el uso continuo de dibujos, esquemas y herramientas. Palabras clave: matemáticas en la escuela primaria. Metodología de enseñanza de las matemáticas de Singapur. Didáctica de las Matemáticas y Gamificación. Enseñanza de Matemáticas y Juegos. 


\section{Introdução}

A utilização de metodologias inovadoras no ensino da Matemática é algo que torna a aprendizagem mais significativa para os educandos. Para que isso seja possível, entretanto, nós educadores precisamos superar práticas reprodutivas e substituí-las por dinâmicas através das quais os alunos possam desenvolver mais do que sua memória: que despertem seu espírito crítico, sua criatividade, sua capacidade de raciocínio lógico. Dentro dessa proposta, cabe colocar como objetivo desse trabalho estudar a Metodologia de Singapura e a aplicação de suas ferramentas didáticas e confeccionar, aplicar e avaliar um Jogo para os professores trabalharem com suas turmas do Ensino Fundamental, envolvendo operações matemáticas básicas e frações, dentro do Método de Resolução de Problemas de Singapura.

Inicialmente, nos baseamos em uma análise crítica e qualitativa de uma sequência de atividades selecionadas de uma coleção de livros didáticos de Singapura, cujas competências se fazem presentes no currículo do ensino básico brasileiro e de uma pesquisa bibliográfica sobre a metodologia do ensino da Matemática nas séries iniciais do Ensino Fundamental utilizada em Singapura.

Esse artigo foi dividido em três seções. Na primeira seção discutiremos brevemente sobre essa Metodologia de ensino: Por que ela é considerada uma das melhores do mundo? Quais seus diferenciais nas estratégias de resolução de operações matemáticas básicas? Falaremos sobre a importância da resolução de problemas no ensino da Matemática e qual o método utilizado para a resolução de problemas no ensino dessa disciplina em Singapura e estudaremos a resolução de um problema utilizando o Modelo de Barras. Já na segunda seção, conceituaremos gamificação, falaremos sobre os benefícios da sua aplicação e iniciaremos o processo de gamificação da Metodologia de Singapura, misturando jogos e resolução de problemas e apresentando o nosso produto, o jogo Problemix. Finalizando, na terceira seção faremos um breve relato sobre a aplicação do jogo Problemix em duas turmas de quinto ano do Ensino 
Fundamental I apresentaremos os dados coletados pelos questionários respondidos através da análise de gráficos, seguidos pelas considerações finais e referências.

\section{A matemática de Singapura}

Nos estudos internacionais que avaliam o desempenho dos alunos em Matemática, Singapura ocupa sempre um lugar de destaque. Esse sucesso se deve a um investimento em estratégias de ensino eficazes e a implementação de programas que estão sempre buscando melhorias na educação matemática. Essa metodologia incentiva à criança a relacionar e compreender melhor os conteúdos lecionados, evitando a memorização sem sentido, os procedimentos repetitivos, os cálculos massacrantes.

A Metodologia de Singapura baseia-se em Compreender, Consolidar, Transferir e Avaliar, onde o mais importante é aprender, não decorar, sempre enfatizando não o "como" e sim o "por quê?". E para compreender, necessita abstrair os conceitos e esquematizar. Deve consolidar o suficiente para poder transferir antes de avaliar, seja através da socialização com os colegas, de discussões em grupo ou de práticas.

Outro fato importante que chama atenção na Metodologia de Educação Matemática de Singapura é que, ao contrário da maioria das escolas brasileiras, eles não se preocupam em repassar todo o conteúdo do ano letivo e sim, avançar o conteúdo apenas quando os educandos aprenderem o tema proposto completamente. $\mathrm{O}$ lema é: "Devagar se aprende mais". Assim, a Matemática se torna mais sólida e é menos provável que os educandos tenham que repetir aqueles conteúdos, pois quando realmente aprendem não os esquecem com tanta facilidade.

Além disso, pode-se dizer que a ênfase do método de educação matemática de Singapura é, com certeza, a resolução de problemas através de múltiplas representações. Nesta abordagem prevê-se a manipulação de materiais, a representação pictórica, esquemática e, por fim, a representação simbólica (a construção de proposições matemáticas abstratas), sendo os problemas bem trabalhados, o que fazem total diferença no aprendizado. 
A metodologia de Singapura enfatiza a resolução de problemas em todas as fases do aprendizado, desenvolvendo conceitos e processos, trabalhando habilidades e atitudes, criando uma experiência de metacognição.

Além da resolução de problemas em si, fazem parte da metodologia de educação matemática de Singapura a utilização das ferramentas "Number Bond"; "Family Facts Numbers" e "Bar Model". A ideia é a de que, para qualquer situação-problema seja utilizada pelo menos uma ferramenta matemática. É claro que, dependendo da situação, algumas ferramentas são mais adequadas que outras. Como diz Sutherland: "É importante que os estudantes desenvolvam um repertório de ferramentas matemáticas diferentes e uma consciência do uso apropriado em diferentes situações" (2009, p. 54-55).

O Number Bond (NB) é utilizado em todo o processo de aprendizagem do número e das quatro operações aritméticas básicas. Para utilizar o NB, o educando deve analisar cada situação ou problema e descobrir a decomposição numérica mais conveniente. Exemplo: $7=5+2$ ou $7=4+3$ ou $7=6+1$, etc. Nesse exemplo o "Number Bond" é o número representado no lado esquerdo (sete) que é decomposto em duas partes, de três formas diferentes, para generalizar a ideia de parte-todo e de comparação. Essa ferramenta pode ser muito útil na divisão, como podemos ver no exemplo abaixo (figura 1).

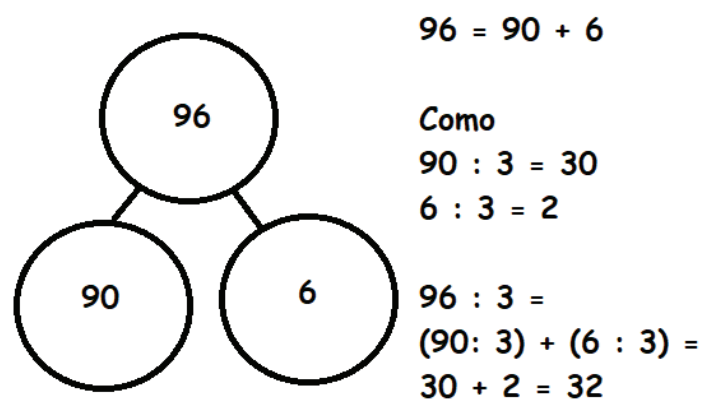

Figura 1- Number Bond na divisão.

Fonte: Elaborada pela autora (2019) 
Já a ferramenta "Fact Family Numbers", nada mais é do que explorar as possibilidades de operações com um conjunto de números dentro da adição e da subtração, relacionando-os. Por exemplo, entre [7, 5 e 2]: $7-2=5,7-5=2,5+2=7$ e $2+5=7$. Neste tipo de tarefa devem ser exploradas todas as hipóteses existentes

O "Modeling Bar" ou "Bar Model" (Modelo de Barras) é utilizado desde as séries iniciais e essa técnica é desenvolvida ao longo dos anos escolares. Trata-se da visualização pictórica na passagem entre o concreto e o abstrato. Além de ser uma ferramenta para a resolução de problemas, o Modelo de Barras utilizado em Singapura também pode ser um ótimo aliado para explicar conceitos matemáticos, principalmente quando se trata das operações com frações. Além disso, pode-se pensar também nesta estratégia como uma aprendizagem gradual da Álgebra. Como diz Fernandes (2017), "Todo este processo de representação pictórica e generalização é um sistema de abstração que a criança concretiza e deve vivenciar, do mais simples ao mais complexo".

Através desse método, toda resolução de problemas passa por alguns passos: além da leitura e coleta de dados, pela fase concreta que é a compreensão do problema através da manipulação de materiais concretos (prática), a fase pictórica, que é realizada por uma representação esquemática (visual) e por fim pela representação simbólica (fase abstrata). Assim, o educando tem uma compreensão bem detalhada do problema, facilitando a sua resolução. Essa abordagem é denominada CPA (Concreto + Pictorial + Abstrato).

Para a fase concreta, essa metodologia utiliza, geralmente, o Modelo de Barras. O currículo de Singapura usa os diagramas para contextualizar o problema e o esquema visual para permitir que o educando compreenda melhor a situação problemática.

Observe a forma como foi resolvido esse problema: Sam, Ravi e Elliott tinham juntos 92 bolinhas de gude. Sam tem três vezes mais bolinhas de gude que Ravi e Ravi tem duas bolinhas de gude a menos que Elliott. Quantas bolinhas de gude Ravi possui? 


\section{In Focus}

Sam, Ravi and Elliott have 92 marbles altogether. Sam has 3 times as many marbles as Ravi. Ravi has 2 fewer marbles than Elliott. How many marbles does Ravi have?

\section{Let's Learn}

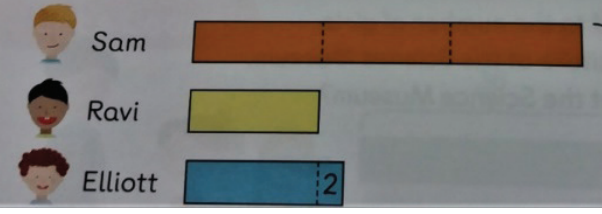

Figura 2- Interpretando Problemas.

Fonte: "Math - No Problem!", Textbook 3A (2014, p. 160).

A Figura 2 mostra os primeiros passos do método de resolução de problemas. Os três personagens foram desenhados, proporcionando um estímulo visual. Ao lado dos seus nomes, barrinhas desenhadas de forma proporcional, representando a quantidade ainda não sabida de bolinhas de gude de cada um, com relação ao Ravi. Na Figura 3, observamos que, para uma contagem mais facilitada, retiraram-se as duas bolinhas a mais que Elliott tinha e, consequentemente, do total de bolinhas, que passou a ser 90 .

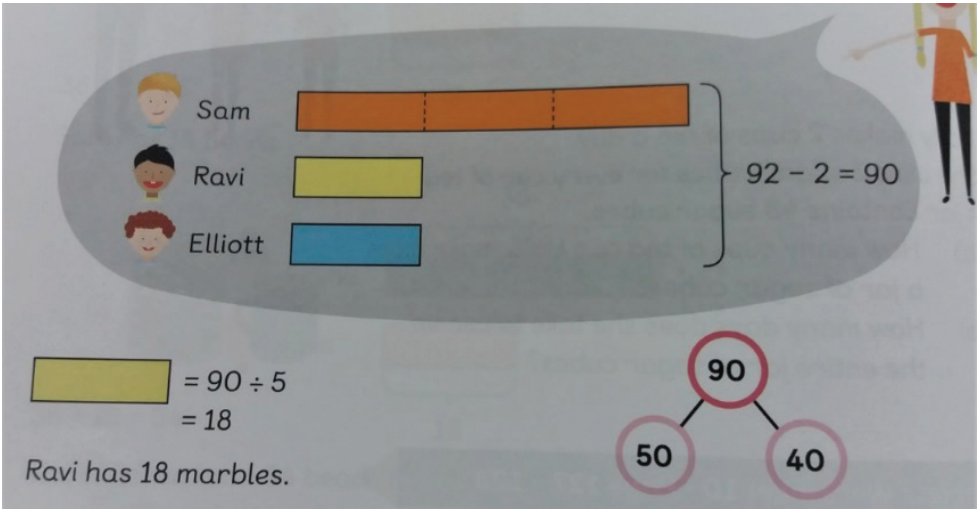

Figura 3- Resolvendo Problemas 2

Fonte: “Math - No Problem!', Textbook 3A (2014, p. 160). 
Assim, pode-se dividir o total de bolinhas em 5 partes iguais, descobrindo o número de bolinhas de gude que Ravi possui. Para fazer a divisão, também foi utilizado o conceito de NB, desmembrando 90 em partes de 50 e 40. Então, a divisão torna-se mais fácil, pois só precisamos dividir 40 por 5 , que é 8 , já que cabe uma vez 50 dentro de 90, logo,

Dessa forma, um problema que, no Brasil, costumamos trabalhar com os nossos estudantes apenas no oitavo ano do Ensino Fundamental II, quando ensinamos Sistemas de Equações do Primeiro Grau, em Singapura, é trabalhado nas séries iniciais do Ensino Fundamental I, de uma forma lúdica, onde todos compreendem, sem precisar saber nada sobre sistemas ou equações.

\section{Gamificando a metodologia de Singapura}

Usar jogos ou elementos de jogos dentro de um contexto educacional. Isso é Gamificar. É quando o educador utiliza jogos ou elementos desses em sala de aula, envolvendo um ou mais conteúdos, com o objetivo de proporcionar um aprendizado significativo para o educando, trabalhando o conteúdo de uma forma lúdica. A utilização de Jogos com objetivo pedagógico pode ser realizada dentro e fora de sala, como forma de iniciar, desenvolver ou revisar conteúdos.

Os benefícios da utilização de Jogos na educação são muitos, quando jogamos controlamos diferentes variáveis ao mesmo tempo, somos desafiados, observamos e aprendemos a cumprir regras, aprendemos conceitos, traçamos estratégias e planejamos ações, refletimos diante de situações problemáticas e resolvemos problemas, desenvolvemos a criatividade e a criticidade reflexiva, a autonomia, a iniciativa, aprendemos a colaborar e pedir ajuda, a trabalhar em equipe, a ser persistentes, lidamos com a competição e também com a frustração de nem sempre ganhar, mantemos uma meta e ações que precisamos lidar e, além de tudo, nos divertimos.

A aplicação de Jogos em sala de aula traz diversos benefícios, entre eles: conseguimos identificar alunos com dificuldade; temos um retorno se o conteúdo está sendo bem assimilado ou não; por existir uma competição 
entre os jogadores, que almejam vencer, ocorre um aperfeiçoamento dos educandos, que tentam se superar durante o desenrolar do jogo; os alunos tornam-se mais críticos e confiantes, expressando o que pensam, elaborando perguntas e tirando conclusões; não existe o medo de errar, pois o erro é um degrau necessário para se chegar a uma resposta correta; e o aluno se empolga com uma aula diferente. Por tudo isso, os Jogos podem ser vistos como ferramentas de aprendizagem de uma forma lúdica e divertida. (HOLETZ, 2019, p. 156)

Segundo Smole (2007), o jogo envolve o desafio, a surpresa, a possibilidade de fazer de novo, de querer superar os obstáculos iniciais e o incômodo por não controlar todos os resultados (p. 10) e "é esse interesse que suscita a necessidade de aprender, a vontade de jogar e o desafio de vencer um obstáculo apresentado". (p. 15)

Outra grande contribuição para a educação que o Jogo proporciona é o aprendizado através dos erros. Isso porque o que pode ser algo "doloroso" nas aulas tradicionais, na realização de um Jogo é algo considerado normal, pois faz parte do processo de qualquer jogo você ter que repetir várias e várias vezes uma fase para conseguir subir de nível. Assim, o erro pode ser algo realmente construtivo, pois, através dele, o educando reflete sobre o que fez, procura identificar o motivo do seu erro e busca outra estratégia para resolver seu problema, aprendendo com ele. Como diz Holetz (2018), diante de um impasse, surge a necessidade de buscar novas soluções, desenvolvendo assim a criatividade. A ideia é aprender errando, manipulando e vivenciando. Um verdadeiro exercício de superação.

No jogo, os erros são revistos de forma natural na ação das jogadas, sem deixar marcas negativas, mas proporcionando novas tentativas, estimulando previsões e checagem. O planejamento de melhores jogadas e a utilização de conhecimentos adquiridos anteriormente proporcionam a aquisição de novas ideias e novos conhecimentos. (SMOLE, 2007, p. 10)

Na Matemática, a utilização de Jogos em sala de aula é ainda mais benéfica, pois desenvolve com grande potencialidade o raciocínio lógico-matemático e amplia o desenvolvimento e escolhas de estratégias dos educandos. 


\subsection{O Jogo Problemix}

Durante o Ensino Fundamental I, os educandos devem aprender a realizar todas as operações básicas da Matemática e também os conceitos e as operações com frações, ambos fundamentais para o desenvolvimento do raciocínio matemático do aluno. Essas operações e conceitos ensinados nesse período acadêmico são a base de toda a construção matemática da carreira estudantil dos nossos alunos, por isso são tão importantes e devem ser bem trabalhados.

Para esse propósito criamos o Jogo Problemix: Desenvolvendo Competências Matemáticas básicas diversificadas através da Resolução de Problemas, envolvendo resolução de problemas pelo Método de Singapura: um jogo simples, de pouco custo, que pode ser utilizado em diferentes situações e que, com toda certeza, proporcionará momentos de aprendizado de forma lúdica.

\footnotetext{
Nessa perspectiva, a inserção de jogos no contexto escolar aparece como uma possibilidade altamente significativa no processo de ensino-aprendizagem, por meio da qual, ao mesmo tempo em que se aplica a ideia de aprender brincando, geralmente interesse e prazer, contribui-se para o desenvolvimento cognitivo, afetivo e social dos alunos. (RIBEIRO, 2007, p. 21).
}

A Jogabilidade é simples. Inicialmente, os líderes de cada grupo são chamados pela professora, que disponibiliza várias cartelas com problemas (separadas pelos níveis e com os problemas virados para baixo). O jogo começa com cada um dos líderes, escolhendo aleatoriamente (sem ver os enunciados) um problema do nível 1, e voltando para seus grupos para tentar resolver esse desafio. Cada grupo pegará um desafio por vez, começando todos pelo mesmo nível e aumentando de acordo com o ritmo de cada grupo. Com o desafio em mãos, os integrantes do grupo irão discutir e tentar resolver o problema solicitado, fazendo seus registros individuais.

Para cumprir cada nível do jogo, os alunos deverão desenvolver algumas competências como: exploração do problema, levantamento de hipóteses, tentativa de solucionar o problema a partir do que já sabem, identificação do que compreendem e o que é preciso 
compreenderem para solucionar o problema, compartilhamento e discussão de informações com a equipe, aplicação do conhecimento para solucionar o problema e avaliação da eficácia do processo utilizado. "A resolução de problemas matemáticos é um processo que possibilita ao aluno compreender de forma significativa os conceitos matemáticos, onde a utilização de situações-problemas dá um sentido prático a aprendizagem”. (FERREIRA, 2014, p. 10)

Para facilitar a compreensão dos problemas, cada grupo poderá ter à disposição, além do material escolar, uma caixa com o Material Dourado e tiras do Modelo de Barras, que poderão utilizar sempre que acharem necessário.

Depois de o grupo chegar a uma solução consensual, em que todos os seus componentes da sua equipe concordam, o secretário registra em uma folha de papel o desenvolvimento das contas realizadas pelo grupo, assim como seu resultado, de acordo com o problema escolhido em cada nível e o líder encaminha a possível solução até a professora, que orientará o educando a pegar uma cartela de um nível superior, caso a resposta estiver correta, ou retomar ao seu grupo para refazer o problema, caso estiver respondido erradamente, possibilitando um repensar do problema pelo grupo, que só passará para novo nível do jogo, quando conseguir resolver corretamente aquele desafio.

$\mathrm{O}$ erro aqui deve ser visto como uma passagem necessária para o aprendizado. Assim como os jogos de videogame de fases, que você precisa vencer um vilão (chefe de fase) para passar para outro nível do jogo e para isso, geralmente, precisa repetir várias vezes aquela etapa, aprendendo com os erros, observando padrões e elaborando novas estratégias de ataque e defesa e até vencê-lo não consegue seguir com o jogo, no Problemix o grupo só passará para o próximo nível quando completar efetivamente o anterior, efetuando a(s) operação(ões) correta(s) e apresentando uma solução consistente. Se isso não acontecer terá que tentar novamente até conseguir.

No meio das cartelas com os problemas, algumas cartelas especiais serão inseridas, que estão intituladas como "Pule o nível" 
e "Escolha o desafio". As cartelas de Pular o nível passam imediatamente para o nível posterior, sem precisar fazer o desafio naquela fase do jogo. Já com a cartela "Escolha o desafio", o líder poderá ver os problemas das demais cartelas daquele nível e escolher o exercício que o grupo irá resolver. Observação: Nesse caso, o líder não poderá escolher uma cartela especial "Pule o nível", caso tenha uma disponível no seu nível.

Cada grupo deverá completar todos os desafios e aquele que completar o último desafio corretamente primeiro é o grande vencedor. Queremos ressaltar, entretanto, que apesar de ser um Jogo de Competição, onde todos os grupos estarão disputando o primeiro lugar, é mais que um jogo de competição, onde apenas um grupo é vencedor. Nesse jogo todos ganham, pois para passar cada nível, todos precisam acertar, refazendo e aprendendo com seus erros. É um jogo de superação e aprendizagem. Além disso, ele só termina quando todos passam por todas as fases. Sendo assim, cada avanço, por si só, já é uma conquista.

Apesar de haver um grupo apenas que será o vencedor, que é o primeiro a passar por todos os desafios satisfatoriamente, aconselha-se que o professor oriente os alunos a continuarem a realizar os desafios até concluírem todos os níveis, e que convidem os alunos dos grupos vencedores a circularem na sala de aula e auxiliarem os demais a concluírem as suas etapas.

Assim, todos ganham: os alunos mais avançados, que aprendem ensinando, os alunos que têm dificuldades, aprendendo com seus erros e posteriormente com os seus colegas, e o professor que consegue, de uma forma lúdica, conquistar a atenção dos seus alunos e retomar o conteúdo lecionado, oportunizando que seus alunos ponham em prática seus conhecimentos e esclareçam suas dúvidas brincando.

Os professores que atuam com educação básica compreendem que aliar tecnologia ao currículo permite diversificadas formas de interação: professor — aluno, aluno - professor, aluno — aluno; oferece informações variadas, superficiais ou aprofundadas, sobre todos os assuntos; torna a aula mais 
agradável e com maior interesse por parte dos alunos; expande a aprendizagem para além da sala de aula e da escola; favorece a socialização dos saberes; auxilia na inclusão digital tanto de alunos como dos próprios professores. (ALMEIDA; ALMEIDA; FERNANDES JUNIOR, 2018, p. 611)

Para avaliar o desempenho dos seus alunos durante o desenvolvimento do Jogo Problemix, o professor orientador poderá observar a interação do grupo, a participação dos integrantes na elaboração das tentativas de resolução do Jogo e no desenvolvimento dos registros individuais e na manipulação dos materiais em sala, no desempenho do líder e na atuação e registros do secretário de cada grupo.

No final do Jogo, o professor também pode sugerir uma avaliação do Jogo e da participação do grupo, que pode ser inicialmente feita de forma oral, onde cada um pode, voluntariamente, falar sobre o jogo, o que gostou ou não, o que aprendeu, que estratégia utilizou para resolver um determinado problema, etc. Os alunos que terminaram antes e ajudaram os colegas também podem ser convidados a relatarem essa experiência. Nesse momento dá para observar bem quem realmente aprendeu alguma coisa com o jogo, quem se dedicou para ensinar os outros e quem colocou a mão na massa. Esses relatos serão importantes para o educador avaliar a atuação dos seus alunos e também o aproveitamento do Jogo.

\section{Análise de dados da aplicação do Jogo Problemix}

A aplicação do Jogo Problemix foi realizada na Escola Municipal Professora Ilka Muller de Mello, localizada no bairro de Gravatá, em Navegantes, em duas turmas de $5^{\circ}$ ano do Ensino Fundamental I, compostas por 18 alunos no período matutino e 23 alunos no período vespertino e que possuem a mesma professora como regente.

Foi possível observar que enquanto a turma do período matutino em geral tinha bastante interesse e facilidade com a Matemática, no período vespertino, a grande maioria dos alunos tinha difi- 
culdade com o conteúdo e eram mais reservados, não se sentindo muito livres para opinar ou perguntar e tirar suas dúvidas, apesar de serem muitas. Outro fato que me chamou a atenção foi que boa parte dos alunos do período vespertino não quiseram ajudar os colegas quando terminaram suas atividades, o que foi realmente o oposto do que aconteceu de manhã, onde os alunos foram solícitos com os demais e realmente colocaram a "mão na massa", tutoriando os que tinham mais dificuldade.

Durante a realização desses experimentos de gamificação foram realizados os procedimentos de observação, registros e documentação fotográfica. Após, foram aplicados questionários aos alunos participantes do jogo de ambas as turmas, com o objetivo de identificar o aproveitamento dos alunos, benefícios e dificuldades encontradas, além dos relatos sobre a aceitação da proposta (ou não) pelos alunos.

Após a coleta dos dados, os mesmos foram classificados de forma sistemática através de seleção (exame minucioso dos dados), codificação (técnica operacional de categorização) e tabulação (disposição dos dados de forma a verificar as inter-relações). Foram categorizadas entrevistas de 17 alunos dos quintos anos do turno matutino e 23 de alunos dos quintos anos do turno vespertino.

A primeira pergunta do questionário aplicado refere-se ao nível de satisfação dos educandos quanto ao processo de gamificação nas aulas de Matemática através da aplicação de um jogo. Dos 40 alunos entrevistados, 33 gostaram ou amaram essa experiência (mais de $82 \%$ ) e nenhum relatou que não gostou, o que nos motiva ainda mais para continuar esse trabalho. A professora inclusive, em conversa informal, nos relatou que dificilmente tem tempo para realizar alguma atividade gamificada, o que tornava essa prática incomum para aqueles estudantes.

A próxima pergunta feita foi sobre se os educandos consideraram o conteúdo cobrado nos problemas do jogo adequado ao que eles já tinham visto em sala de aula. Aqui existe um viés interessante. Basicamente, todo o conteúdo trabalhado nos problemas 
que fazem parte do jogo é visto até o quinto ano, pois constitui em operações básicas e frações, entretanto, dois dos conteúdos inseridos no meio e no final do desenvolvimento do jogo não são conteúdos contemplados até esta série no ensino fundamental I, no Brasil. Como o conteúdo do Jogo foi adaptado dos livros da coleção "Math no Problem!", da Metodologia de Singapura, inserimos dois assuntos dentro dos demais de forma sutil, que são Sistemas do Primeiro Grau e Princípio Fundamental da Contagem, conteúdos do oitavo e nono ano do Ensino Fundamental II.

\section{O que você achou de ter aulas de Matemática baseadas na aplicação de umjJogo?}

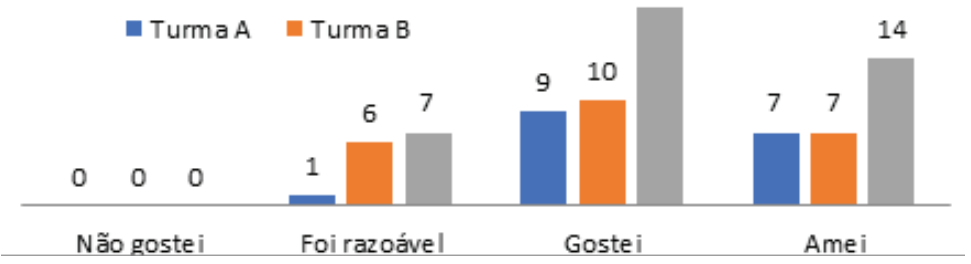

Figura 4 - Gamificação nas aulas de Matemática

Fonte: Elaborada pela autora (2019)
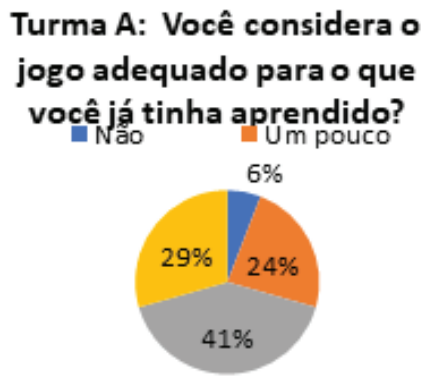

\section{Turma B: Você considera o jogo adequado para o que você já tinha aprendido?}

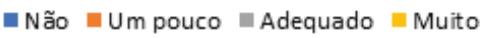

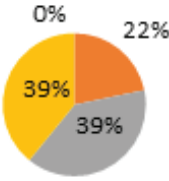

Figura 5 - Adequação de Conteúdos

Fonte: Elaborado pelos autores (2019).

Pelo gráfico, podemos observar que 30 das 40 pessoas entrevistadas consideraram os conteúdos vistos no jogo adequados ou muito adequados. Apenas um dos alunos da turma A (matutino) 
observaram que no jogo tinha conteúdo ainda não visto. E realmente, mesmo com dificuldades, os grupos conseguiram concluir os desafios, mesmo aqueles que não eram parte do currículo escolar regular. Uma coisa importante que a Metodologia de Singapura nos ensina é que podemos trabalhar conteúdos mais avançados em séries iniciais, desde que esses conteúdos estejam contextualizados e que o nosso foco, como educadores, esteja voltado às diferentes formas de resolução e à utilização de formas e esquemas visuais adequados para facilitar a compreensão dos nossos educandos.

Outra pergunta se refere aos desenhos e esquemas contidos nas cartelas e as peças utilizadas para resolver os problemas do jogo. Uma das principais características da Metodologia de Singapura é justamente a utilização de recursos visuais na resolução de problemas. E essa foi uma preocupação grande que tivemos, de sempre utilizar algo visual para representar ou facilitar a resolução do problema, como é em Singapura. Usamos Modelos de Barras e o Number Bond sempre que possível

Quando chegaram no nível 3, onde se deparavam com uma multiplicação por números grandes, por exemplo, dos onze grupos que participaram do jogo, reparei que apenas um menino de um grupo do matutino utilizou o recurso dado na cartela realizando a multiplicação através da soma do dados (como na multiplicação por áreas).

Exemplo: Se $2000 \times 30=60000,300 \times 30=9000$ e $50 \times 30$ $=1500$, calcule $2350 \times 30$.

Ora, como $2350=2000+300+50,2350 \times 30=(2000+$ $300+50) \times 30$, ou seja, $2000 \times 30+300 \times 30+50 \times 30$, logo, basta somar $60000+9000+1500=70500$, mas em vez de fazer a soma, os alunos faziam a multiplicação tradicional, pois era o que estavam mais acostumados, mesmo sendo um procedimento bem mais lento. Acredito, inclusive, pela conversa que tive com eles no final do jogo, que a grande maioria dos educandos nem tinha se tocado dessa possibilidade antes de eu comentar. 
Assim, muitas vezes os desenhos, como as barras de frações já praticamente davam as indicações para as respostas dos problemas ou, no mínimo, indicavam sua interpretação, porém, grande parte dos alunos nem prestava atenção nos desenhos, acredito que por falta de costume mesmo, culpa nossa, pois nós, professores brasileiros, estamos acostumados a trabalhar Matemática apenas com algoritmos e álgebra, deixando muito cedo de lado essa tão importante ferramenta visual.

Podemos perceber pelo gráfico que cerca de $47 \%$ dos alunos usou pouco ou nem utilizou os desenhos e esquemas contidos nas cartelas. Já 53\% dos estudantes usaram os desenhos, sendo que $25 \%$ usou muito, inclusive um dos grupos que venceu o jogo, realizando os desafios corretamente e mais rápido que os demais falou que os desenhos ajudaram bastante e que eles davam "dicas" para resolver os problemas.

A pergunta posterior foi se os educandos ajudaram seus colegas na resolução dos problemas. Do total de entrevistados, 10\% se considerou incapaz de ajudar os colegas, três deles da turma vespertina, que visivelmente tinha muitos alunos com dificuldades em Matemática; 20\% acredita que ajudou seus colegas um pouco, $45 \%$ acredita que fez um bom trabalho ajudando os colegas e $25 \%$ que ajudou muito, contribuindo efetivamente para o grupo e para os demais colegas de sala depois que acabaram sua parte.

\section{Você ajudou os seus colegas na resolução dos problemas?}

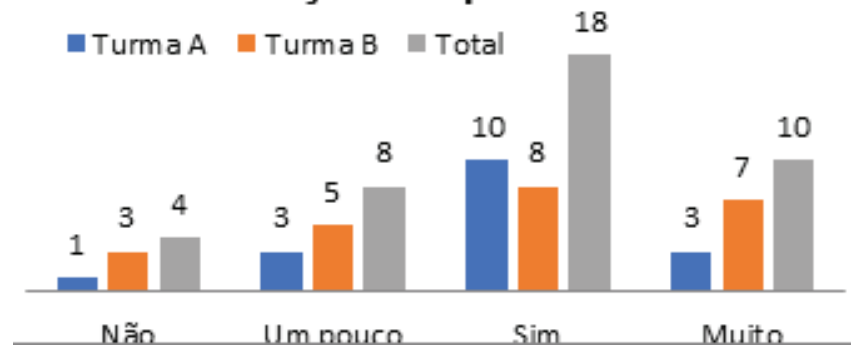

Figura 6 - Ajuda aos colegas

Fonte: Elaborada pela autora (2019) 
Perguntado se eles se sentiram aprendendo com os colegas, quase a metade dos participantes (47\%) responderam que sim e 18\% que aprenderam muito, e ninguém não se sentiu aprendendo com os colegas durante a realização do jogo. Esse foi um resultando bastante satisfatório.

Para finalizar, queremos deixar registrado que quando perguntando informalmente no final da atividade aos alunos quais os níveis que eles tiveram mais dificuldade, quais os problemas mais difíceis, muitos ainda falaram frações, mas a grande maioria achou os problemas envolvendo sistemas os mais complicados o que estaria totalmente coerente com o que já lhes foi ensinado, entretanto, como diz Sutherland (2009), “...é importante ter consciência de que os estudantes provavelmente já podem resolver qualquer problema que for apresentado com uma ferramenta alternativa" (p. 57)

Por exemplo, um aluno do nono ano ou Ensino Médio, provavelmente resolverá um problema envolvendo Sistemas de Equações através de algum método aprendido de resolução de sistemas, como o Método da Adição ou da Substituição, mas o mesmo problema nas mãos de um aluno do quinto ou sexto ano, que ainda não aprendeu nada sobre Equações do Primeiro Grau e muito menos sobre Sistemas, provavelmente será resolvido através de tentativa e erro ou ainda, através de desenhos ou esquemas, mas não quer dizer que ele não irá conseguir solucioná-lo. Aqui está a beleza da Matemática. Um mesmo problema, sendo solucionado de diferentes formas, utilizando conhecimentos diferentes, mas todos com seu valor.

\section{Considerações finais}

O coração da Metodologia do ensino da Matemática de Singapura é, com toda certeza, a resolução de problemas, que são propostos de diferenciadas formas, promovendo o crescimento do pensamento matemático do educando. Essa metodologia trabalha com o desenvolvimento da compreensão de conceitos antes das técnicas, utilizando uma abordagem visual e concreta que antecede a aprendizagem formal da matemática, tornando tudo mais sim- 
ples. Seu ponto forte é a utilização de recursos visuais e o uso de ferramentas pedagógicas que simplificam muito na interpretação e auxiliam na resolução dos problemas matemáticos. Dentre as principais ferramentas destacam-se o Number Bonds, que trabalha com o raciocínio-lógico matemático simples dentro das operações básicas e é muito bem utilizado, assim como os Modelos de Barras, que são usados em todos os tipos de problemas, inclusive aqueles que não trabalham com frações.

Nada na Matemática de Singapura é decoreba ou repetição. Tudo é explicado através de exemplos visuais e é contextualizado, tornando-se um aprendizado significativo para o aluno. Enquanto nós brasileiros estamos preocupados com a quantidade de conteúdos a ser dado, sempre preocupados com o tempo, eles se preocupam com a qualidade desses conteúdos.

Para trabalhar com essa metodologia dentro da nossa realidade propomos a criação de um jogo, que denominamos Problemix. Algo simples para os professores imprimirem e realizarem com seus alunos sem muito stress e sem muito custo. Colorido, com muitos desenhos e esquemas que facilitam o entendimento do problema. Estimulando o registro, trabalhando com problemas o tempo todo, e, principalmente, desestigmatizando as frações. No final, existe um aprendizado cooperativo. Onde aqueles mais avançados podem ajudar os demais, ensinando, apreendendo juntos.

De uma forma bastante simplificada, acrescentamos problemas de conteúdos mais avançados no jogo, e pudemos observar na prática que o uso dos modelos de barras e da experimentação visual tão característica de Singapura torna algo possivelmente problemático em algo tranquilo, mostrando que é possível trabalhar conceitos vistos nas últimas séries dos anos finais nos anos iniciais sem problemas.

De modo geral, a pesquisa evidenciou que a gamificação através do jogo Problemix apresentou bom potencial para promover a aprendizagem dos alunos e de uma forma lúdica, já que o jogo teve uma boa aceitação por parte dos educandos (mais de 
$82 \%$ aprovaram a gamificação da aula), 65\% dos alunos se sentiram aprendendo durante o jogo e apenas um, dentre 40 alunos, acreditou que o jogo estava inadequado para os conteúdos que eles estavam aprendendo, sendo que havia dois conteúdos que nem faziam parte dos conteúdos ministrados no Ensino Fundamental I. Por meio destes resultados, é possível concluir que a gamificação aplicada como estratégia de aprendizagem ativa pode ser considerada uma ótima ferramenta para deixar os alunos focados, motivados e felizes, e com a possibilidade de aprender se divertindo.

\section{Referências}

ALMEIDA, Fernando J.; ALMEIDA, Siderly C. D.; FERNANDES JUNIOR, Alvaro M. Cultura digital na escola: um estudo a partir dos relatórios de Políticas públicas no Brasil. Revista Diálogo Educacional, Curitiba, v. 15, n. 58, 2018. Disponível em https://periodicos.pucpr.br/index.php/dialogoeducacional/article/view/24228 Acesso em 01 jul. 2020.

FERNANDES, Dárida. Sendas de Sucesso com o "Método de Singapura". Maio de 2017. Partes 1, 2 e 3. Disponível em: < https://www.cfaematosinhos.eu/ Edozarfaxinarsn70.htm $>$ Acesso em 12/12/18.

FERREIRA, Meryellen Roberta Ferreira. Um caminho estratégico para a resolução de problemas na sala de aula para alunos do $6^{\circ}$ ano do ensino fundamental. Os desafios da escola pública do Paraná em uma perspectiva do professor. Artigos 2014. Versão Online disponível em: < http://www.diaadiaeducacao.pr.gov. br/portals/cadernospde/pdebusca/producoes_pde/2014/2014_uenp_mat_artigo_meryellen_roberta_ferreira.pdf> Acessado em 22/12/2018.

HOLETZ, M. S. Aprendendo e se divertindo: Uma Proposta de Gamificação nas Aulas de Apoio de Matemática. Artigo disponível em: SCALABRIN, Caren. (org.) Anais Completos. Colóquio Internacional de Educação, [S.l.], v. 4, n. 1, out. 2018. ISSN 2595-8003. P. 631 - 634. Disponível em: <http://editora.unoesc.edu. br/index.php/coloquiointernacional/article/view/19681/10433>. Acesso em: 29 Nov. 2018.

HOLETZ, M. S. Educandos satisfeitos, aprendendo matemática e se divertindo com isso: uma proposta de intervenção através da gamificação nas aulas de apoio pedagógico. In: GARCIA, Marilene. (org.) Projetos de Metodologias Ativas: Trabalhando diversas realidades educacionais. Curitiba: Artesanato Educacional, 2019. p. $151-171$. 
RIBEIRO, Flávia Dias. Jogos e Modelagem na Educação Matemática. Curitiba: Saraiva, 2007.

SMOLE, Kátia Stocco; DINIZ, Maria Ignez; MILANI, Estela. Cadernos do Mathema: Jogos de Matemática de $6^{\circ}$ a $9^{\circ}$ ano. Porto Alegre, Editora Artmed, 2007.

SUTHERLAND, Rosamund. Ensino Eficaz da Matemática. Porto Alegre: Artmed, 2009. 